
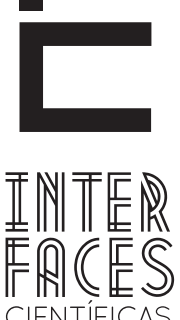

CIENTÍFICAS

HUMANASE SOCIAIS

\title{
ESPAÇOS, PRÁTICAS E CONSUMO DE CULTURA E ENTRETENIMENTO PELA JUVENTUDE DE SALVADOR NO BAIRRO DO RIO VERMELHO
}

Sergio Sobreira Araujo'

\section{RESUMO}

As práticas e o consumo de cultura na atualidade estão imbricados com os sentidos do entretenimento, de modo que a fruição cultural possibilita a irrupção de novos significados para os contextos identitários. Em decorrência da reformulação das configurações societárias pela incorporação das tecnologias digitais, são definidos novos paradigmas para a sociabilidade e a convivência, sobretudo entre a população mais jovem. Com base em tais pressupostos, este trabalho se dispôs a examinar, através da análise de dados obtidos em pesquisa de campo, as relações, as práticas, os espaços e o consumo de cultura na popu- lação entre os 18 e 35 anos, tendo por lócus o bairro do Rio Vermelho, em Salvador/Bahia, reconhecido como lugar de boemia, cultura e entretenimento na capital baiana. É um território com características que ilustram os modos de ser e viver de parcela da juventude contemporânea e que possibilitam a indicação de alguns atributos e especificidades desse segmento populacional.

\section{PALAVRAS-CHAVE}

Cultura. Consumo. Juventude. Rio Vermelho. 


\section{ABSTRACT}

The practices and consumption of culture today are interwoven with the senses of entertainment, so that the cultural enjoyment enables the eruption of new meanings for identity contexts. Due to the redesign of corporate settings by incorporating digital technologies, new paradigms are defined for sociability and conviviality, especially among the younger population. Based on these assumptions, this study set out to examine, through the analysis of data obtained in field research, relationships, practices, spaces and consumption of culture in the population between 18 and 35 years, locus by taking the neighborhood of Rio Vermelho in Salvador/Bahia, recognized as a place of bohemian, culture and entertainment in Salvador. It is a territory with features that illustrate the ways of being and living part of contemporary youth and enabling the display of some attributes and characteristics of this population segment.

\section{KEYWORDS}

Culture. Consumption. Youth. Rio Vermelho.

\section{RESUMEN}

Las prácticas y el consumo de cultura en la actualidad están imbricados con los sentidos del entretenimiento, de modo que la fruición cultural posibilita la irrupción de nuevos significados para los contextos de identidad. Como resultado de la reformulación de las configuraciones societarias por la incorporación de las tecnologías digitales, son definidos nuevos paradigmas para la sociabilidad y la convivencia, sobre todo entre la populación más joven. Con base en tales presupuestos, este trabajo se dispuso a examinar, a través del análisis de datos obtenidos en pesquisa de campo, las relaciones, las prácticas, los espacios y el consumo de cultura en la populación entre los 18 y 35 años, teniendo por lócus el barrio del Rio Vermelho, en Salvador/Bahía, reconocido como lugar de bohemia, cultura y entretenimiento en la capital baiana. Es un territorio con características que ilustran los modos de ser y vivir de parcela de la juventud contemporánea y que posibilitan la indicación de algunos atributos y especificidades de ese segmento de la población.

\section{PALABRAS CLAVE}

Cultura. Consumo. Juventud. Rio Vermelho.

\section{BREVES CONSIDERACÕ̃ES SOBRE CONCEITOS, DI- MENSÕESE CONSUMODECULTURA NA ATUALIDADE}

0 mundo em que vivemos é caracterizado pela radicalidade e velocidade com que tem mudado tanto nas externalidades que the conformam quanto nas dinâmicas que the regem. São mudanças que decorrem, sobretudo, dos impactos produzidos pelas mudanças tecnológicas, especialmente no campo das comunicações. O fluxo de informações, imagens, sons e dados apoiado em alta tecnologia tem se intensificado nos últimos 40 anos e é quase impossível de ser contido por fronteiras territoriais e barreiras ideológicas. Configura-se uma sociedade em rede de tal sorte complexa, tantos são os vetores, direções, conexões e níveis, que qualquer enunciação já parte do pressuposto de limitação de capacidade para apreender, compreender e explicar a realidade.

As transformações decorrentes deste contexto tem alterado profundamente a produção de sentidos, com 
especial repercussão sobre o campo da cultura, de tal sorte que definir e conceituar cultura se tornou tarefa das mais complexas. Como advertiu Jean Claude Passerou, cultura "é o mais proteiforme dos conceitos sociológicos [...] é o termo que leva ao labirinto mais vertiginoso de uma biblioteca babeliana" (PASSERON In DONNAT et TOLILA, 2003, p.369). O percurso conceitual do termo cultura evidencia essa dificuldade. 0 primeiro conceito formal veio de Tylor (1871), segundo o qual cultura seria "todo complexo que inclui conhecimentos, crenças, arte, moral, leis, costumes ou qualquer outra capacidade ou hábitos adquiridos pelo homem como membro de uma sociedade" (TYLOR apud LARAIA, 2005, p.25). Seguiram-se a ele diversos pensadores (Hegel, Durkheim, Marcel Mauss, Max Weber, Georg Simmel, Walter Benjamim, Theodor Adorno, Max Horkheimer, Raymond Williams, Richard Hoggard, Stuart Hall, Terry Eagleton, Homi Bhaba, Clifford Geertz, Dick Hebdige, Pierre Bourdieu, para citar os mais destacados) e postulados teóricos (da sociologia clássica, do estruturalismo, do pós-estruturalismo, dos estudos culturais, dentre outros) que, segundo os matizes ideológicos e o ambiente epistêmico em que se situavam, ora dilatavam, ora restringiam o que caberia dentro do esteio conceitual da cultura. Diante de tantas perspectivas e no exercício de busca de síntese, para este artigo foi adotada a proposição de Laurent Fleury (2009) que define que, na contemporaneidade, a palavra "cultura" expressa três sentidos heterogêneos: "como estilo de vida, [...] como comportamento declarativo [...] e como corpus de obras valorizadas".

É uma perspectiva que se complementa com a argumentação de José Márcio Barros quando propõe que importante é reconhecer que, em qualquer sociedade, tempo histórico ou conjuntura, a cultura teve, tem e terá um caráter central e insubstituível: o ordenamento, a classificação e a comunicação das coisas do mundo pelos sentidos a elas atribuídos (BARROS, 2002). A argumentação de Barros é consorciada com a tese de que a cultura é marcada por "três dimensões centrais e interdependentes: a política, a econômica e a social" (BARROS, 2002).
Isaura Botelho (2001) propõe outra perspectiva: a cultura é perpassada por duas dimensões: antropológica e sociológica, mas ressalva que "embora as duas dimensões [...] sejam igualmente importantes, do ponto de vista de uma política pública exigem estratégias diferentes". A autora esclarece que "na dimensão antropológica, a cultura se produz através da interação social dos indivíduos", portanto, os modos de ser, agir e sentir permitem a construção de "pequenos mundos de sentido", enquanto que a dimensão sociológica "não se constitui no plano do cotidiano do indivíduo, mas sim em âmbito especializado", referindo-se a "uma produção elaborada com a intenção explícita de construir determinados sentidos e de alcançar algum tipo de público, através de meios específicos de expressão", caso das linguagens e formas de expressão artísticas.

As múltiplas dimensões da cultura estão associadas também às profundas modificações sofridas pelas noções de trabalho e de lazer ao longo do século XX, entregando ao atual século demandas por informação e entretenimento bastante diversificadas das que se conhecia em um passado recente. A arte, como expressão primordial de tudo que o homem cria para comunicar e revelar sua subjetividade, foi contaminada pelas novas instâncias de percepção e de conteúdos das emoções, sensações, sentimentos, valores, ideias, conceitos e teses que formam a multiplicidade de sentidos da condição humana. A autonomia da arte e o seu uso condicionado por fatores não-estéticos, predominatemente mercadológicos, foi apontado por Canclini em Culturas Híbridas:

\footnotetext{
A autonomia do campo artístico, baseada em critérios estéticos fixados por artistas e críticos, é diminuída pelas novas determinações que a arte sofre de um mercado em rápida expansão, onde são decisivas forças extraculturais. [...] os agentes encarregados de administrar a qualidficação do que é artístico - museus, bienais, revistas, grandes prêmios internacionais - reorganizam-se em relação às novas tecnologias de promoção mercantil e de consumo. (CANCLINI, 1998, p.56)
} 
Um dos componentes fundamentais para compreensão das transformações sociais, o processo de urbanização, também passou por uma violenta aceleração nesse período. Mais e mais pessoas passaram a viver nas cidades, demandando que o espaço urbano instituísse e diversificasse a oferta de serviços. Maior tempo ocioso para empregar em outras atividades, maior disponibilidade para experimentar, maior capacidade econômica para consumir, são fatores que, combinados entre si e a outros igualmente convergentes com a dinâmica do entretenimento, tem levado a reconfiguração das práticas culturais. Por outro lado, a fruição da cultura, antes predominantemente atrelada ao sentido burguês de aquisição de "verniz civilizatório", tem se deslocado para a incorporação do potencial hedonista de obtenção de prazer através das dimensões de entretenimento que predominam sobre o cultural na atualidade.

Quaisquer que sejam as dimensões da cultura na contemporaneidade, parece inquestionável ter que se reconhecer a transversalidade da cultura pela economia. Fenômenos como a crescente mercantilização da arte e as novas teses sobre o papel da cultura no desenvolvimento econômico, os usos e empregos da cultura para as mais diversas finalidades, até alcançar às especificidades da cultura como campo de produção, mercado e consumo de bens e serviços, são indicadores que preconizam que a economia da cultura é um campo promissor. Por ser um campo em formação, ainda demanda a realização de mais estudos que the autonomizem enquanto epistemologia, inclusive para fornecer contornos mais claros e precisos sobre a im- bricação da cultura pelos sentidos do entretenimento e destes com o valor de mercado que thes conferem potencial econômico.

Contudo, a percepção do consumo de cultura vai além do fato econômico, como sustenta Canclini, ao propor que o consumo deve ser analisado em perspectiva muito mais ampliada:

O consumo serve para pensar, partimos da hipótese de que, quando selecionamos os bens e nos apropriamos deles, definimos o que consideramos publicamente valioso, bem como os modos com que nos integramos e nos distinguimos na sociedade, com que combinamos o pragmático e o aprazível (CANCLINI, 1995, p.21)

Por outro lado, é preciso admitir que o mercado, substituiu a política e a ideologia como meio de encaminhamento e resolução das questões sociais, contaminando, em largas medidas, a noção que se tem de cidadania. Canclini (1995, p.31) indaga que "devemos nos perguntar se ao consumir não estamos fazendo algo que sustenta, nutre e, até certo ponto, constitui uma nova maneira de ser(mos) cidadãos". A análise do público e as expressões de suas externalidades (comportamentos, hábitos, práticas, preferências, tendências, etc.) podem indicar caminhos que respondam a tal questionamento. O lugar do consumo na juventude, especialmente de cultura e entretenimento, é o que este artigo pretende evocar como uma das chaves de interpretação dos novos contornos que o cultural tem adquirido na contemporaneidade.

\section{SALVADOR/RIO VERMELHO: A CIDADE, UM BAIRRO E SUA JUVENTUDE}

Salvador é uma cidade que ilustra com propriedade o fenômeno da expansão urbana. A população em quarenta anos passou de 1.007.195 (1970) para 2.998 .906 (2010) habitantes, fazendo com que a re- 
lação entre práticas culturais e espacialidades venha sofrendo alterações substantivas na formação de novos públicos, novos hábitos, novos mercados, novas demandas e novos arranjos na forma como bens, produtos e serviços culturais são colocados para a sociedade. Trata-se de uma população majoritariamente jovem, com $61,2 \%$ da população com idade até 29 anos (IBGE, 2010), o que contribui para que se tenha o que Maffesoli (2005) chama de "cultura juvenil contemporânea" com suas tribos, seus hábitos e suas novas formas de sociabilidade.

Por outro lado, a primeira capital brasileira, maior cidade do Nordeste e terceira maior do Brasil, projeta-se, historicamente, no cenário nacional como um centro de criação, produção, mediação e difusão de arte e cultura. Ao longo de sua história entregou ao país um vasto repertório de formas e conteúdos culturais, que ajudaram de forma substancial a formar os contornos da identidade brasileira. Diversas são as expressões culturais associadas à cidade como a capoeira; o samba; as religiões de matriz africana, seus símbolos, ícones e as formas derivadas de seus rituais que se expressam em formas populares da música e da dança; a gastronomia baseada no azeite de dendê e na mandioca, entre outras. Do mesmo modo, importantes manifestações e movimentos artísticos brasileiros como o Cinema Novo, o Tropicalismo e a Axé Music, igualmente se relacionam, umbilicalmente, com a cidade.

Em que pese à diversidade cultural que sempre caracterizou Salvador, nas últimas décadas a capital baiana, como lócus criativo no campo das artes e da cultura, passou a ser referenciada por sua vocação para o entretenimento e a festa, tendo como público preferencial o segmento jovem da população, assim entendida a faixa etária que vai dos 18 aos 35 anos. Esta referência se consolidou em decorrência da expansão que os produtos culturais relacionados ao contexto do carnaval passaram a ter, sobretudo nos circuitos midiáticos e mercadológicos. Dentre deste contexto, a supremacia das formas culturais rela- cionadas ao contexto da festa - os gêneros e estilos musicais conhecidos como axé music, pagode baiano, arrocha e, mais recentemente, forró e sertanejo em seus derivativos "eletrônico" e "universitário" - no sistema cultural da cidade é constatada pela prevalência massiva destes produtos musicais nas mídias e nos espaços culturais. É uma situação que forma um quadro de tensões e ausências, já alçado a condição de objeto de diversos estudos e pesquisas no âmbito acadêmico, no qual surgiu a designação "monocultura do axé", para denunciar o que parece ser a presença avassaladora de determinados formatos em prejuízo daquilo que se nomearia como diversidade, posto que restringe e condena às margens e aos guetos os demais formatos. Apesar de essa acepção estar longe de ser consensual, para este artigo será considerada a perspectiva de que a hegemonia formada por esta vertente é comprovada e gera implicações ponderáveis na espacialidade, nas práticas e no consumo de cultura de Salvador.

Na configuração espacial da cidade, o bairro do Rio Vermelho é considerado um dos territórios da boemia, com uma concentração significativa de mais de uma centena de bares, restaurantes, teatros, casas de shows e outros espaços, nos quais as atividades artísticas e culturais orientadas ao entretenimento do público jovem são largamente encontradas. Entretanto, ao contrário da já citada "monocultura do axé”, o que prevalece neste território, é que ali se encontra uma multiplicidade de formas e estilos que restituem à cidade sua vocação para o diverso e o plural.

Localizado na orla atlântica de Salvador e mesclando glebas residenciais com concentrações de pontos comerciais e de serviços, o Rio Vermelho é considerado um bairro integrante da área nobre da cidade, ao mesmo tempo em que abriga ainda uma das maiores festas populares da Bahia, a Festa de Yemanjá que ocorre anualmente no dia 2 de fevereiro e reúne milhares de pessoas pelo bairro nas atividades de devoção aquele orixá, entre festas, batucadas, feijoadas, shows, etc. 
Apesar de estar matizado pela grande afluência do público jovem e de contar com construções e empreendimentos mobiliários modernos, o bairro também integra os sítios históricos de Salvador, tanto pela presença de diversas construções do período colonial, como pelo fato de estar marcado pela participação na formação da cidade. Foi ali na praia do Rio Vermelho em 1510 que Diogo Álvares Correia, desembarcou como único sobrevivente do naufrágio de seu navio, tendo sido acolhido pelos índios tupinambás que ali habitavam. Dos índios ganhou o nome de Caramuru (moreia) e casou-se com a índia Paraguassú, formando a primeira família brasileira miscigenada. As ruas do bairro estão carregadas de história e cultura que acabam compondo o alicerce "mágico" para o sistema comercial desse local. Os espaços que ali se encon- tram são objeto de interesse de empresários que buscam lucro com o entretenimento.

Com características tão marcantes e singulares, o local foi escolhido para a prática de pesquisa de uma turma de determinada disciplina ministrada pelo autor em Universidade sediada em Salvador. A pesquisa documental que norteou a realização da pesquisa e os dados coletados a partir da pesquisa de campo (aplicação de questionários e realização de entrevistas) subsidiaram a realização deste artigo que se propõe a examinar as práticas, os espaços e o consumo de cultura pela parcela da população jovem de Salvador que frequenta o bairro do Rio Vermelho, de forma a compreender as dinâmicas e os processos culturais em curso naquele território.

\section{AS PRÁTICAS E O CONSUMO DE CULTURA PELO PÚBLICO JOVEM NOS ESPAÇOS CULTURAIS E DE ENTRETENIMENTO DO BAIRRO DO RIO VERMELHO}

Quando se iniciou a delimitação do corpus da pesquisa sobre as práticas, os espaços e o consumo de cultura no bairro do Rio Vermelho pela turma de alunos do autor, um conjunto de informações prévias, algumas já citadas na primeira seção desse artigo, enunciava um horizonte preliminarmente conhecido sobre o que iria ser estudado. Mesmo assim, haviam lacunas a serem preenchidas. De saída, havia o desafio de se chegar à definição e recorte da amostragem: quantos lugares constituíam o universo de espaços a serem considerados como parte do território a ser pesquisado? Que critérios e que extratos censitários seriam adotados para os procedimentos de seleção do tamanho da amostra? Que fundamentos estatísticos nos dariam o tamanho ideal dessa amostra?

Entre bares, restaurantes, casas de espetáculos, teatros, galerias de arte, videolocadoras, bibliote- cas e centros culturais, o Rio Vermelho possui pouco mais de uma centena de estabelecimentos, sendo que mais de $60 \%$ deles oferece alguma atividade artística ou cultural, como elemento principal ou acessório, a maioria com foco no entretenimento. 0 conjunto de espaços contidos nessa amostra é amplamente heterogêneo. São lugares voltados para distintos perfis de consumo, com atrações e estilos de vários gêneros, fazendo com que a diversidade da amostra fosse o primeiro desafio a ser enfrentado.

Procedeu-se ao mapeamento destes lugares e foram selecionados aqueles em que a oferta de atividades artístico-culturais fosse regular. Após esse primeiro recorte, constituiu-se o banco de dados com as características básicas do funcionamento dos locais selecionados para o delineamento do perfil de cada 
um. Foram encontradas as seguintes formas artísticas: música, teatro, dança, artes plásticas e visuais, leitura e literatura, sendo que a música destacou-se como a atividade mais presente e em maior quantidade de oferta. De posse destas informações, procedeu-se a escolha dos locais onde a pesquisa seria aplicada, delimitando-se o segundo recorte: foram selecionados dez espaços, sendo seis dedicados à música (dos mais variados estilos), um teatro, uma biblioteca, uma galeria de arte e um espaço cultural multiuso. Os locais escolhidos atendiam ao critério da regularidade de funcionamento e programação e eram portadores de maior recall entre os demais: Varanda do SESI (Música - MPB / Samba / Pop / Reggae / Rock), 30 Segundos (Música - Pop / Rock / Música Eletrônica), Portela Café (Dança, Teatro, Música - Eletrônica, Pop / Rock), Botequim São Jorge (Música - MPB / Samba), Padaria Bar (Música - MPB / Samba / Pop / Reggae / Rock), Sunshine (Música - MPB / Pop / Reggae / Rock), Teatro SESI (Teatro, Dança e Música), Biblioteca Juracy Magalhães Jr. (Literatura e Leitura), RV Galeria (Artes Gráficas e Visuais) e Mídia Louca (Música/Audiovisual e espaço multiuso para shows e eventos).

A etapa seguinte foi de definição das demais opções metodológicas, seguida da formatação dos instrumentos de pesquisa. Duas instâncias de coleta de dados foram adotadas: 1 - realização de entrevistas com produtores e gestores dos espaços selecionados para conhecer a dinâmica de gestão e produção das atividades artístico-culturais desenvolvidas; 2 - aplicação de questionários junto ao público frequentador e consumidor destes espaços, para conhecer seu perfil, através dos dados censitários e dos hábitos de consumo. 0 tamanho da amostra - aleatória simples - foi definido pela realização de dez entrevistas e aplicação de cem questionários, divididos igualmente para cada local selecionado.

A elaboração do questionário e do roteiro de perguntas da entrevista foi feita pela turma levando em conta os pressupostos estabelecidos nos objetivos da pesquisa. Pesquisas e entrevistas similares foram consultadas e ajudaram a subsidiar a criação e elaboração dos instrumentos de pesquisa. Para o questionário prevaleceram os dados censitários básicos (sexo, idade, escolaridade, renda familiar, estado civil) e os dados sobre as práticas e o consumo de cultura-entretenimento (incidência e frequência de visitação, gasto médio, meio de transporte utilizado, meios de comunicação acionados para se informar sobre a programação, além da opinião sobre atratividades, potencialidades, infraestrutura e problemas existentes). 0 roteiro de questões das entrevistas priorizou aspectos da gestão e da produção (o que, como, onde, quando e quanto produz em bens, serviços e produtos culturais, que estratégias e instrumentos de gestão e produção são adotadas, que tipo de informação e conhecimento tem sobre seu público, como dimensiona e avalia seu mercado, que ações de promoção faz, como se relaciona como os mecanismos de fomento, patrocínio, captação de recursos, que dificuldades encontra e que potencialidades vê para seu negócio).

A ida a campo foi extensa (cerca de três semanas) devido à dificuldade no agendamento e realização das entrevistas. Depois que os dados foram coletados e tabulados, veio o trabalho de análise e crítica das informações para elaboração do resultado e redação do relatório final. 0 extrato desta análise proporcionou os seguintes indicadores:

1. SEXO - Há um equilíbrio na frequência entre o público masculino (52\%) e feminino (48\%), sobretudo nos espaços de música. As exceções vieram da RV Galeria (Artes Visuais) onde a amostra encontrou $80 \%$ de homens e $20 \%$ de mulheres; e da Biblioteca Juracy Magalhães (leitura e literatura) e do Teatro Sesi (Artes Cênicas) com $70 \%$ mulheres e 30\% homens.

2. ORIENTAÇAO SEXUAL - 85\% se declararam heterossexuas, enquanto $4 \%$ se declaram homossexuais e $3 \%$ se declararam bissexuais. $8 \%$ preferiram não responder. 0 resultado da amostra converge com outras pesquisas sobre o assunto: as sexualidades não normativas oscilam em torno de $10 \%$ do total da população. 
3. IDADE - A opção metodológica foi de aplicar questionários a quem estivesse presente nos locais selecionados, de forma a não direcionar para uma única faixa etária e assim, verificar inclusive, se a estimativa de que a predominância do público seria ratificada ou retificada. Quase metade do público (43\%) pesquisado está entre 18 a 25, enquanto na faixa etária de 26 a 35 está a segunda maior parcela da amostra (30\%), caracterizando o público do rio vermelho como essencialmente jovem (73\%).

4. ESTADO CIVIL - Com $5 \%$ de divorciados, $12 \%$ de casados e $20 \%$ estão em um relacionamento estável, a maioria (63\%) é de solteiros, o que confere ao Rio Vermelho uma aura de que é o local ideal para a "paquera", a "azaração", elementos igualmente atrativos para o público jovem.

5. ESCOLARIDADE - A maioria do público está na universidade (41\%) seguido de perto pelas pessoas com ensino superior completo (30\%) e pós-graduados (8\%), o que reflete que o público possui instrução elevada para os padrões brasileiros.

6. RENDA FAMILIAR - Foi adotado o Critério Padrão de Classificação Econômica Brasil 2008 da Associação Brasileira de Empresas de Pesquisa (Abep) e da Associação Brasileira de Antropologia (Aba). Com base nesse sistema, identificou-se que os públicos das classes A (34\%), B (29\%) e C (33\%), formam a quase totalidade da amostra populacional, explicitando que o bairro se destina ao consumo de cultura e entretenimento das classes médias e da classe alta.

7. FREQUÊNCIA DE VISITA - Enquanto $13 \%$ estava naquele local pela primeira vez e $36 \%$ se afirmava ser frequentador esporádico, sem regularidade declarada, $51 \%$ do público é fidelizado: frequenta os espaços culturais do bairro mais de uma vez por semana.

8. MEIO DE TRANSPORTE - A maioria do público possui meio próprio de locomoção (59\%) enquanto uma parcela declarou estar utilizando táxi (13\%) e ônibus (22\%). 0 restante (6\%), morador do próprio bairro, não precisou de meio de transporte. A condição econômica privilegiada explica essa autonomia em relação aos transportes públicos.

9. VALOR GASTO - Foram instituídas seis faixas de consumo médio. A maioria (30\%) declarou gastar entre R\$ 51 e R\$100, seguida da parcela do público (20\%) com gastos na faixa de $\mathrm{R} \$ 31$ a $\mathrm{R} \$ 50$. As demais parcelas, $17 \%$ (R\$ 21 a R\$ 30), 14\% (R\$ 11 a R\$20), $10 \%$ (acima de R\$100) e $9 \%$ (abaixo de R\$10), formavam a outra metade da amostra. Os gastos declarados foram com ingressos ou pagamento de couvert artístico e alimentos e bebidas.

10. MEIO DE INFORMAÇÃO - Para esse tópico foi permitido que mais de uma resposta fosse validada, considerando que é habitual a busca cruzada por mais de um meio de informação sobre opções de lazer, atrações, entretenimento e espaços culturais. As respostas mais frequentes foram o "boca a boca" (58\%), seguido pelo uso e consulta da internet e redes sociais (55\%). Considerando que as redes socias são espaços de interação entre pessoas que muitas vezes se conhecem de fora da rede, e que também comportam formas não promocionais de divulgação, estimamos que a opinião de amigos e/ou pessoas que são reputados como formadores de opinião, tem um papel fundamental no processo de disseminação - difusão de informação sobre programação/agenda cultural e entretenimento.

11. ÍNDICE DE SATISFAÇÃO - A maioria (58\%) está satisfeita com a programação e a qualidade dos serviços prestados pelos espaços. $35 \%$ se declararam parcialmente satisfeitos, enquanto a insatisfação ficou na faixa dos $6 \%$.

12. DEMANDAS (LACUNAS E/OU POTENCIALIDADES) - Há um equilibrio do público com relação ao portfólio de serviços e produtos oferecidos no bairro do Rio Vermelho: $50 \%$ sentem falta de outros serviços e produtos, como cinema e livrarias, enquanto $50 \%$ não sentem falta de nada. 
13. ATRATIVIDADE - A aura de boemia e de "azaração" constitui o grande capital de atratividade do bairro do Rio Vermelho, pois a quase totalidade das respostas destacou esses atributos.

14. PRINCIPAIS PROBLEMAS - Também para esse tópico foi admitido mais de uma resposta. As maiores reclamações recaíram sobre a falta de segurança (79\%), falta de estacionamento (72\%) e deficiência da limpeza urbana (53\%), problemas relativamente comuns às grandes cidades e que tiveram um recrudescimento em Salvador nos últimos anos pelos inúmeros problemas de gestão nas administrações públicas do município e do Estado.

A análise das entrevistas evidenciou relativa homogeneidade nas respostas. Produtores e gestores mostra uma preocupação contínua com a viabilidade econômica de seus empreendimentos, afinal, são iniciativas privadas que pouco se relacionam com as políticas públicas de fomento e, por não dependerem do Estado, só contam com o mercado como esteio de sua viabili-

\section{CONCLUSÕES}

A convergência e o cruzamento entre os dados e as informações, oriundas dos questionários e das entrevistas levou a uma série de considerações de caráter conclusivo, mas de alcance de enunciação relativo, tendo em vista que a envergadura e alcance da pesquisa são declaradamente limitados. Ainda assim, alguns resultados chamaram a atenção e surpreenderam diante da ideia que se tinha antes da pesquisa, baseada no senso comum, sobre as dinâmicas culturais do bairro e o que se imaginava ser o perfil predominante do público frequentador: jovens de 18 a 35 anos.

De saída, chama a atenção o fato de que, dentro da amostra de público, a maioria possua renda dade e permanência. Então, as apostas artísticas são também mercadológicas e, mesmo as mais ousadas em termos artísticos, são pautadas pela medida do cálculo do retorno financeiro. Para tanto, existe uma atenção constante em compreender quem são os públicos de seus eventos/espaços e como manter os canais de comunicação abertos com esses públicos.

Por outro lado, a relativa mobilidade dos gostos e preferências do público jovem, particularmente atento e desejoso por novidades, tem demandado dos produtores e gestores a aquisição e exercício da sensibilidade para saber que gostos precisam ser atendidos e satisfeitos. Nesse sentido, alguns entrevistados mostraram-se antenados em conhecer e acompanhar o mercado musical de entretenimento (no caso do Rio Vermelho, o que se poderia chamar de mercado baiano não hegemônico, já que a vocação deste território, como já foi dito, é por outros estilos e gêneros, fora da tríade axé music/pagode/arrocha) para poder inserir em suas programações aquilo que, estima-se, faça parte do desejo de consumo do público.

própria acima de dez salários mínimos, revelando uma população jovem economicamente e independente, portadora de uma autonomia e capacidade de consumo ponderável. Nesse sentido, é admissível fazer uma conexão entre a alta escolaridade e a maior exposição a circuitos de informações e notícias, que levam esse público a exercer seu poder de escolha com maior protagonismo. Ainda que a ambiência cultural e de entretenimento em Salvador favoreça o largo predomínio de algumas formas sobre outras, a parcela que frequenta o bairro do Rio Vermelho consorcia poder econômico com uso e consumo da diversidade. 
Por outro lado, ao revelar a apropriação do que se nomeia como diversidade cultural pela população com maior poder de consumo e informação, indica que os nós da distribuição e do acesso permanecem muito bem amarrados, não convertendo a riqueza da diversidade cultural em bem comum, ainda que muitas vezes seja oriunda das camadas mais populares. Amartya Sen defende com rigor que o desenvolvimento de um povo está essencialmente ligado às oportunidades que oferece à população de fazer escolhas e exercer sua cidadania. A sociedade contemporânea convive com uma opulência sem precedentes permeada por privações e opressão extraordinárias. O desenvolvimento consiste na eliminação das privações de liberdades que limitam as escolhas e as oportunidades das pessoas de exercerem sua condição de cidadãos (REIS, 2007). A democracia do acesso só se realiza quando o controle da distribuição é pulverizado. A diversidade - um dos valores centrais da cultura - fica enfraquecida quando não há livre circulação de sua produção. Daí que resta uma questão emblemática da quão complexa é a discussão: como falar em desenvolvimento cultural quando a distribuição de produtos e serviços culturais é controlada por um grupo restrito de corporações? Sem livre acesso não há desenvolvimento nem democracia plena.

Outro aspecto de destaque é a alta taxa de fidelização do público com o bairro. Alguns comentários foram registrados pelos pesquisadores acerca das falas dos entrevistados enaltecendo que o Rio Vermelho é um local de encontro de amigos. É onde todos estão, onde todos se encontram. Essa ação de reunir os amigos se vê refletida nos meios de informação que esse público utiliza: o "boca-a-boca" e a interação pelas redes sociais, sobretudo Twitter e Facebook, que também requerem a esfera da "amizade" como permeio de interação. Por outro lado identifica-se uma contradição entra essa fidelidade, também possível de ser traduzida (nesse caso) como acomodação, e o que normalmente se espera (ou se imagina) desse público, que é ter um maior apetite, quase uma necessidade, por consumir novidades, mudanças.
Os termos do embate entre novidade x permanência podem ser relativizados se forem considerados dois aspectos cruciais acerca do bairro e da cidade: o Rio Vermelho possui uma significativa diversidade de atrações e espaços culturais diante do que o resto da cidade tem a oferecer, a atmosfera de boemia do bairro faz com que as pessoas se sintam em seu território; por outro lado, Salvador tem atravessado uma fase de precarização que alcança a cidade em muitas latitudes, desde a crônica falta de infraestrutura ao agravamento dos problemas com violência, segurança, etc. o que possivelmente leva uma parcela do público a preferir estar em local onde se "sente em casa".

Por fim, cabe observar como é instigante a predominância avassaladora das formas culturais destinadas ao entretenimento, em sentido estrito, sobre qualquer outra que se relacione com o contexto clássico em que se inscreveram as funções da arte: educação para a sensibilidade; questionamento e aprimoramento moral e ético; elaboração estética; reflexão e o questionamento das coisas do mundo; proposição e revisão dos modos de ser e viver; expressão da subjetividade humana em todas as suas dimensões; dentre outros elementos que instituem o que se convencionou chamar de evolução em direção a permanente jornada civilizatória. $O$ fato de estar se vivendo um interregno entre duas eras, em que o sistema de valores de uma época cai em desuso enquanto outro emerge, torna ainda mais difícil a apreciação deste fenômeno, posto que não se tem novos parâmetros que permitam observar a atualidade com propriedade, ainda mais quando a era em que se vive está marcada pela busca do divertimento em termos tão voláteis quanto fulgazes. 0 instantâneo, o múltiplo, o efêmero e o simultâneo mesclados à fragmentariedade e velocidade, são características que passam a prevalecer nesse mundo de ambiência digital e que, possivelmente, podem estar contribuindo pela busca do prazer imediato como motor das relações e das ações humanas que demarca 0 atual momento geracional da juventude. 


\section{REFERÊNCIAS}

ARAUJO, Sérgio Sobreira. Produção Cultural no contexto das Políticas Públicas: uma análise da trajetória do teatro baiano profissional no período de 1988 a 2010. (Tese de Doutorado). Programa Multidisciplinar de Pós-Graduação em Cultura e Sociedade. Salvador: UFBA, 2011.

BARROS, José Márcio. Caderno do Seminário Projetos Culturais: Mitos e Realidades. Circuito Cultural Banco do Brasil. Editado pela instituição sem créditos ou ficha catalográfica: 2002, p. 5-71.

BARROS, José Márcio. Diversidade Cultural: da proteção à promoção. Belo Horizonte: Autêntica, 2008.

BEHAMOU, Françoise. A Economia da Cultura. Cotia: Ateliê Editorial, 2007.

BOTELHO, Isaura. As dimensões da cultura e o lugar das políticas públicas. Revista São Paulo em Perspectiva. São Paulo, v.15, n.2, abril/junho de 2001. Não paginado. Disponível em <http://www.scielo.br>.

BOURDIEU, Pierre. A economia das trocas simbólicas. 6. ed. São Paulo: Perspectiva, 2009.

CANCLINI, Néstor Garcia. "consumidores do século XXI, cidadãos do século XVIII". In: Consumidores e Cidadãos: Conflitos multiculturais da globalização. Trad. Maurício Santana Dias e Javier Rapp. Rio de Janeiro: Editora UFRJ, 1995. p. 13-47.
CANCLINI, Néstor Garcia. "Das utopias ao mercado". In: Culturas híbridas: estratégias para entrar e sair da modernidade. Trad. Ana Regina Lessa e Heloísa Pezza Cintrão. São Paulo: EDUSP, 1998. p. 31-66.

FLEURY, Laurent. Sociologia da Cultura e das práticas culturais. São Paulo: Senac, 2009.

MAFFESOLI, Michel. Cultura e comunicação juvenis. In Comunicação, mídia e consumo. Trad. Douglas F. Barros. São Paulo: ESPM, 2005. Vol. 2, n.4, p.11-27.

PASSERON, Jean-Claude. Consommation er réception de la culture: la démocratisation des publics. In: Olivier Donnat \& Paulo Tolila (orgs.). Le(s) Public(s) de la culture. Paris: Presses de Sciences Po., 2003, p.369.

REIS, Ana Carla. A Economia da cultura e desenvolvimento sustentável. $O$ caleidoscópio da cultura. Barueri, São Paulo: Manole, 2007.

SEN, Amartya. Desenvolvimento como liberdade. São Paulo: Companhia das Letras, 2000.

YÚDICE, George. A Conveniência da Cultura: usos da cultura na era global. Belo Horizonte: Editora da UFMG, 2004. 